\title{
NILAI DAN MANFAAT YANG TERKANDUNG \\ DALAM SILASA I
}

\section{VALUES AND ADVANTAGES AS REFLECTED IN SILASA I}

\author{
Mustafa \\ Balai Bahasa Provinsi Sulawesi Selatan dan Provinsi Sulawesi Barat \\ Jalan Sultan Alauddin Km 7 Talasalapang, Makassar \\ Telepon (0411) 882401, Faksimile (0411) 882403 \\ Pos-el: lamadaremmeng@gmail.com
}

\begin{abstract}
Absract
The purpose of this research is to express cultural values and advantages reflected in Silasa I (title of a book of Buginese ancestors' moral advices). Originally, these advices were only spoken verbally by older people. The type of oral literature is still alive among the Buginese community. The advices have been mostly inventoried. However, the studies on these advices in Silasa I have not been sufficiently done and met expectations of Buginese literature observers yet. The data of this research are collected through library research and field study. The results indicate that there are cultural values in Silasa; (1) honesty, (2) the nature of envy, bravery, cowardness, and (3) responsibility. While the advantages of Silasa serve as; (1) a reference of moral advices,(2) a philosophy of life, and (3) an interrelationship ties.
\end{abstract}

Keywords: Silasa, Buginese ancestors' moral advices, cultural values

\begin{abstract}
Abstrak
Penelitian ini untuk mengungkapkan nilai budaya dan manfaat yang direfleksikan dalam Silasa I (nama sebuah buku kumpulan petuah-petuah leluhur Bugis). Awal mula petuah-petuah ini hanya diucapkan secara lisan atau dituturkan oleh orang-orang tua. Jenis sastra lisan ini masih hidup di tengah-tengah masyarakat Bugis. Inventarisasi yang dilakukan terhadap petuah-petuah Bugis (Silasa) ini sudah banyak dibukukan. Namun, kajian-kajian terhadap petuah-petuah yang terkandung dalam Silasa belum banyak dilakukan dan belum memadai harapan pemerhati sastra daerah Bugis. Penelitian ini menggunakan teknik pengumpulan data melalui studi pustaka dan studi lapangan. Hasil pembahasan ditemukan beberapa nilai budaya dalam Silasa, yaitu (1) kejujuran, (2) sirik-berani-penakut, dan (3) tanggung jawab; dan manfaat Silasa sebagai (1) bahan nasihat, (2) falsafah hidup, dan (3) perekat hubungan antarindividu.
\end{abstract}

Kata kunci: Silasa, petuah leluhur Bugis, nilai budaya 


\section{Pendahuluan}

Silasa I merupakannama judul sebuah buku berisi ajaran yang diangkat dari perbendaharaan filsafat Bugis, bersinonim dengan kata-kata: layak, patut, dan baik. Silasa I hingga saat ini masih dipergunakan dan dipelihara oleh masyarakat Bugis untuk menyampaikan kearifan-kearifan hidup dengan cara bersastra.

Petuah yang terkumpul dalam Silasa I merupakan salah satu bentuk ekspresi pikiran dan perasaaan orang Bugis yang sering muncul dalam berbagai peristiwa kehidupan masyarakat, baik peristiwa besar maupun kecil, peristiwa suka maupun duka, misalnya hajatan perkawinan. Pembicara dalam hajatan tersebut sering membumbuinya dengan petuah-petuah leluhur.

Nilai budaya adalah lapisan paling abstrak dan luas ruang lingkupnya. Tingkat ini berisi ide-ide yang mengonsepsikan hal-hal yang paling bernilai dalam kehidupan masyarakat (Koentjaraningrat, 1984: 8). Tulisan ini diharapkan memberi manfaat kepada masyarakat berupa pemahaman nilai yang terkandung di dalam Silasa $I$ itu sendiri. Masyarakat diharapkan dapat mengantisipasi munculnya budayabudaya dari "luar" yang belum tentu sesuai budaya kita yang akibatnya bisa merusak moral anak cucu kita kelak. Selain itu, apa yang diungkapkan melalui Silasa I sangat bermanfaat bagi kehidupan manusia. Sebagai bagian sastra nusantara, Silasa I dapat dijadikan sarana dan penerang yang dapat menuntun manusia untuk menemukan hakikat keberadaannya. Salah satu fungsinya yang sangat menonjol adalah sebagai bahan nasihat, falsafah hidup, dan perekat hubungan antarindividu yang disampaikan dalam bentuk bahasa simbol.
Masalah yang akan dibahas dalam penelitian ini adalah (1) bagaimana nilai moral dalam Silasa I dan (2) manfaat Silasa I bagi generasi muda saat ini. Tujuan tulisan ini adalah mengungkapkan nilai dan manfaat Silasa $I$ bagi generasi muda saat ini. Hasil yang diharapkan adalah sebuah analisis sastra klasik tentang nilai dan manfaat dalam rangka pelestarian warisan budaya melalui penyelamatan, pembinaan, dan pengembangan unsur budaya daerah secara langsung dan tidak langsung, serta bagi masyarakat Bugis, dapat diajarkan kepada siswa-siswa melalui pendidikan formal dan nonformal.

Beberapa hasil tulisan seperti makalah dan hasil penelitian tentang petuah-petuah leluhur yang identik dengan tulisan ini yang dapat penulis catat adalah Nilai Edukatif Pappasengdalam Sastra Bugis (Murmahyati, 2000); Pappaseng Tomatoa Relevansinya dengan Masa Kini (Mustafa, 2010); Pendidikan Nilai dan Karakter dalam Pappaseng: Representasi Norma dan Falsafah Hidup Masyarakat Bugis (Syamsudduha, 2012).

\section{Kerangka Teori}

Kerangka teori yang digunakan sebagai acuan dalam penelitian ini adalah teori pragmatik yang dikembangkan oleh Abrams (dalam Teeuw, 1982: 49--53) yang beranggapan bahwa karya sastra diciptakan pengarang hanyalah berupa alat atau sarana untuk menyampaikan pendidikan kepada pembaca. Objek analisis sastra bukanlah karya sastra sebagai objek estetik, melainkan yang lebih penting adalah tujuan-tujuan atau nilai-nilai (objek ekstraestetik) yang bersifat praktis (pragmatik) yang tercermin dalam karya sastra. Konsep pragmatik memandang bahwa karya sastra memuat nilai atau tujuan yang bermanfaat bagi pembaca, dianggap 
sebagai karya sastra yang baik. Berkenaan dengan itu, Horatius (Teeuw, 1988: 51; dalam Wellek, 1990: 25--37) menyebut sastra itu bersifat dulce et utile 'menyenangkan dan bermanfaat'.

Dengan demikian, pengarang melalui karya sastra mempunyai maksud atau tujuan tertentu yang akan disampaikan bagi pembaca (masyarakat). Salah satu maksud atau tujuan itu adalah agar penikmat lebih beradab dan berbudaya, luas pandangannya, halus perasaannya, dan bagus bahasanya (Enre, 1994: 2). Lebih lanjut The Liang Gie (1976: 38) menambahkan bahwa secara luas, nilai diartikan sebagai sesuatu yang benar, baik, dan indah.

\section{Metode}

Metode yang dipergunakan dalam tulisan ini adalah metode deskriptif kualitatif, yaitu menjelaskan nilai-nilai budaya dan manfaat petuah-petuah leluhur yang terkandung dalam Silasa $I$. Untuk memperoleh data-data akurat, penulis menggunakan teknik sebagai berikut:

1. Teknik observasi (pengamatan) langsung di lokasi penelitian untuk mengetahui data lingkungan serta mengumpulkan naskah yang ada hubungannya dengan petuahpetuah tersebut.

2. Teknik wawancara lapangan dengan beberapa informan.

3. Teknik perekaman sastra lisan langsung dari penuturnya. Hasil rekaman tersebut kemudian ditranskripsikan langsung ke dalam bahasa Indonesia. Jika petuahpetuah disampaikan dalam bahasa daerah, hasil rekaman diterjemahkan dulu ke dalam bahasa Indonesia.

Sumber data tulisan ini diperoleh dari beberapa sumber tertulis dan lisan. Sumber tertulis salah satunya dari Pappasengna to Maccaé ri Luwu sibawa Kajao Laliqdong ri Bone (Enre, 1986),
Nilai-Nilai Utama Kebudayaan Bugis (Rahim, 1985), Ada Sulasana Ugi Masagalaé (Palippui, H, dkk., 1992), dan Persepsi Orang Bugis Makassar tentang Hukum, Negara dan Dunia Luar (Abidin, 1983). Adapun sumber lisan diperoleh dari informan terpilih yang memiliki wawasan luas mengenai latar belakang budaya Bugis, seperti budayawan daerah, tokoh adat di daerah, dan orang-orang tua yang banyak mengetahui adat-istiadat masyarakat Bugis.

\section{Pembahasan}

Penulis memilih petuah-petuah leluhur "Silasa I" sebagai objek kajian melalui pendekatan pragmatik karena petuahpetuah tersebut menggunakan simbolsimbol dan diksi atau pemilihan kata yang sarat yang dengan nilai-nilai moral. Dengan demikian, pembaca akan mengetahui apa dan bagaimana sosok sebenarnya masyarakat Bugis. Untuk kejelasannya akan diuraikan sebagai berikut.

\subsection{Kejujuran}

Kejujuran merupakan satu kata yang amat sederhana. Namun, pada zaman sekarang menjadi sesuatu yang langka dan sangat tinggi harganya. Tanpa kejujuran, mustahil akan tercipta hubungan yang baik dengan sesama manusia. Salah satu kriteria untuk menyatakan baik buruknya atau beradab tidaknya seseorang dapat dilihat dari segi kejujuran. Kejujuran itu baru dapat dibuktikan pada saat seseorang mendapat wewenang untuk mengembangkan suatu amanah.

Dalam Silasa I ditemukan suatu konsep kejujuran yang perlu perlu dilestarikan dalam setiap kegiatan, baik dikalangan pribadi atau individu maupun institusi kemasyarakatan. Kejujuran dalam bahasa Bugis disebut alempureng. Secarah harfiah, lempu bermakna 'lurus'. Dari makna "lurus" ini berkembang 
menjadi 'jujur'. Mari simak petuah yang diucapkan secara dialog berikut.

Arungpone: Aga appongenna annae Kajao?

Kajao : Lempu'e

Arungpone : Aga sabbainna lempu'e?

Kajao : Obbi'e

Arungpone : Aga riangobbireng Kajao?

Kajao : a. Aja' muala aju ripasanrenarekko taniya iko pasanre" $i$.

b. Aja' muala waramparang narekko tania warmparammu.

c. Aja' muala aju riwettawali narekko taniya iko mpettai.

(Machmud, 2001: 17--18)

Terjemahan:

$\begin{array}{ll}\text { Raja Bone } & \text { : Apa pangkal kecakapan } \\ & \text { Kajao? } \\ \text { Kajao } & \text { : Kejujuran } \\ \text { Raja Bone } & \text { : Apa yang menjadi saksi } \\ & \text { kejujuran? } \\ \text { Kajao } & \text { : Panggilan (seruan) } \\ \text { Raja Bone } & \text { : Apa yang diserukan } \\ & \text { Kajao? } \\ \text { Kajao } & \text { : a. Jangan mengambil } \\ & \text { bukan yang engkau } \\ & \text { sandarkan. } \\ & \text { b. Jangan mengambil } \\ & \text { barang-barang yang bukan } \\ & \text { milikmu. } \\ & \text { c. Jangan mengambil kayu } \\ & \text { yang ditetak ujung } \\ & \text { pangkalnya yang bukan } \\ & \text { kamu yang menetaknya. }\end{array}$

Kutipan di atas menggambarkan bahwa seseorang yang jujur tidak dengan mudah segera memutuskan sesuatu hal, tetapi terlebih dahulu mencermatinya. Kejujuran itu merupakan perwujudan dari kebaikan dan kebenaran yang dapat diamalkan demi kepentingan diri sendiri dan masyarakat. Karena dengan mengamalkan seruan tersebut, hidup ini akan aman dan damai. Nilai sebuah perbuatan tidak hanya ditentukan oleh baiknya perbuatan itu, tetapi yang lebih penting adalah kemampuan menjaga kejujurannya dalam bertindak agar tidak menyimpang. Misalnya, orang-orang kampung yang tinggal di desa atau kampung kalau mereka ke kebun atau ke hutan mengambil kayu atau apa saja biasanya menyandarkan atau menetak kedua ujung pangkal kayu atau barang yang sudah diambilnya sebagai tanda sudah berpemilik. Jadi, maksud dari panggilan di sini ialah menyeruhkan secara terbuka agar menghormati hak orang laindi samping mengetahui haknya sendiri. Selanjutnya, mari kita cermati petuah yang terkandung Silasa I berikut ini.

"Sabbinna lempu'e limai:
a. Narekko salainaengauwi asalanna.
b. Narekko'rionroi ala naddampengengngi tau ripasalanna.
c. Narekko' risanrekiwi de'napabelleang.
d. Narekko' rirennuangngi de'napacekowang.
e. Narekko majjanciwi narupaiwi jancinna”.

(Machmud. 2001: 19-20)

Terjemahan:

Bukti dari kejujuran ada lima:

a. Kalau bersalah ia mengakui kesalahannya.

b. Kalau ditempati bersalah ia memaafkan orang yang bersalah.

c. Kalau disandari ia tidak mengecewakan.

d. Kalau dipercaya ia tidak menipu.

e. Kalau berjanji ia menepati janjinya.

Kutipan di atas menunjukkan bahwa bertindak dan berprilaku jujur 
dalam segala tindak anamat dibutuhkan dalam segala tindakan yang wajib dimiliki oleh setiap individu karena kepercayaan itu adalah modal utama seorang dalam bertindak, bersosialisasi dengan masyarakat sekitar. Orang jujur menganggap penipuan sebagai sesuatu yang bertentangan dengan paham kebenaran yang dianut serta harga dirinya. Bagi orang jujur, janji itu adalah jaminan harga diri yang dapat ditepati.

\subsection{Sirik-Berani-Penakut}

Sirik mempunyai beberapa arti: rasa malu, malu-malu, segan, kehormatan/harga diri atau martabat, menyesali diri, noda atau aib, hina, dan dengki. Ia merupakan sesuatu yang berselubung di dalam lubuk hati yang sangat halus. Itulah sebabnya apabila orang Bugis mengecap seseorang itu sebagai kurang sirik atau "tau degagasiri'na (tidak malu - tidak ada harga dirinya), yang bersangkutan itu tiada lain bagaikan "boneka" belaka. Oleh karena itu, orang berlatar belakang budaya Bugis sangat marah jika dianggap tania tau (bukan orang).

Sirik bukan hanya sekadar pegangan hidup bagi segelintir manusia yang berlatar belakang budaya BugisMakassar, melainkan merupakan falsafah yang menjadi lambang identitas suku Bugis-Makassar (Amir, 1966: 2). Di samping itu, sirik merupakan sesuatu yang bersifat abstrak dan melembaga di dalam masyarakat serta mencakupi berbagai aspek kehidupan. Sirik merupakan suatu sistem nilai rasio kultural dan kepribadian yang merupakan pranata pertahanan harga diri dan martabak manusia, baik sebagai makhluk individu maupun sebagai makhluk sosial (Abidin, 1983: XIII). Mattulada (dalam Moein, 1977: 33-34) memandangsirik sebagai suatu konsepyang mengintrogasikan secara organissemua unsur pokok dari panngadereng yang oleh Pitirin Sorokin (dalam Rahim, 1985: 138) disebut sebagai norma hukum. Jika diamati nilai-nilai budaya yang tertuang dalam sastra Bugis, khusunya Silasa I, tampaknya nilai sirik itu amat menonjol bahkan bisa dikatakan bahwa nilai-nilai yang lain merupakan penerapan dari nilai sirik ini. Perhatikan petuah di bawah ini.

"Narekko sirikna naranreng
tenritenrengina nariewa"

(Machmud, 2001: 49)

Terjemahan:

Kalau harga diri yang disinggung, tanpa tanggapan pun dilawan.

Petuah tersebut mengisyaratkan setiap orang harus berani menegakkan kehormatan sebagai basis dari terciptanya kehormatan sosial. Hal ini penting karena terabaikannya kehormatan individual akan menyebabkan terjadinya konflik sosial.

Kutipan petuah tersebut di atas juga menjelaskan bahwa sirik adalah hal yang sangat rawan karena menyangkut harga diri. Oleh sebab itu, kalau menyangkut sirik tidak ada lagi jalan lain kecuali langsung mengadakan perlawanan karena keberanian dalam keadaan bahaya adalah suatu kebijaksanaan dalam menghadapi bahaya.

\section{"Tanranna tau waranie}

a. Nappada-pada riengkana enrengnge ride'na;

b. Ce'de'na enrengnge rimaegana;

c. Ripaddiolona nenniya ripaddimonrinna;

d. Rimengkalingana kareba maja' de'natassunrewa nakareba madecen de'natakkauwang."

(Machmud, 2001: 52)

Terjemahan:

Tandanya orang berani 
a. Menyamakan ada atau tidaknya:

b. Sedikit atau banyaknya;

c. Didahulukan atau dibelakangkan;

d. Di saat mendengarkan kabar buruk ia tak gentar dan mendengar kabar baik ia tak menampakkan kegembiraan.

Petuah tersebut menjelaskan bahwa salah satu kelebihan orang berani adalah mampu mengendalikan diri dan perasaannya. Berani, tidak takut dalam keadaan bagaimanapun, termasuk tidak takut melihat susah serta bertanggung jawab, mendorong untuk melaksanakan kewajiban membela negara dan melaksanakan tugas sepenuh hati. Hidup di dunia ini memang aneh, yang banyak dapat meruntuhkan dan sedikit tak dapat menegakkan. Itulah sebabnya maka kemampuan mengendalikan diri dibutuhkan, terutama untuk menghadapi kedua hal tersebut.

"Naiya riassengnge worowane eppai tanrannagau'na nariaseng massipa' makkunrai, aga tenribilanni risesena bilangeng worowane, bettuwanna de'na narirekeng woriwane rirekengmani makkunrai:

a. Makuttui;

b. Maleyai, pellorengngi;

c. Bongngoi;

d. Bebe'i.

(Machmud, 2001: 54)

Terjemahan:

Seorang laki-laki yang memiliki empat ciri tingkah laku yang dapat dikatakan berwatak wanita sebab tidak dianggap laki sebagai laki-laki, maksudnya tidak lagi digolongkan sebagai laki-laki tetapi digolongkan sebagai wanita.
a. Pemalas;
b. Lemah, penakut;
c. Dungu;
d. Bodoh.

Kutipan petuah tersebut menjelaskan bahwa seorang laki-laki mempunyai tanggung jawab yang besar, terutama dalam lingkungan keluarganya. Apabila lemah dan penakut,pastilah ia tak kuat menghadapi tantangan hidup. Demikian juga kalau bodoh dan dungu, dipastikan tidak mampu menyelesaikan dan mengatasi persoalan yang dihadapinya dengan baik, di samping lapangan bergeraknya juga sempit.

Dikalahkan dalam perjuangan karena keadaan yang memaksa adalah soal biasa meskipun memalukan. Akan tetapi, takluk adalah penyerahan secara menyeluruh yang mengikut sertakan seluruh diri. Hal seperti itulah yang banyak tidak dikehendaki oleh manusia Bugis-Makassar. Baginya, lebih baik mati berkalang tanah daripada hidup bercermin bangkai.

\subsection{Tanggung Jawab}

Menurut KBBI (Alwi dkk., 2005: 1139), tanggung jawab adalah keadaan wajib menanggung segala sesuatunya (kalau terjadi apa-apa boleh dituntut, dipersalahkan, diperkarakan, dsb.). Adapun yang dimaksud tanggung jawab dalam tulisan ini adalah kemampuan seseorang mengembang tugas yang dibebankan kepadanya, seperti halnya petuah dalam Silasa I sebagai berikut.

\section{"Iya jujungngi busu'e."}

(Machmud, 2001: 46)

Terjemahan:

Ia yang menjunjung kendi lantas pecah.

Setiap pelaksanaan tugas sebagai mata rantai dari suatu tanggung jawab selalu memerlukan pengorbanan atau risiko. Orang yang sabar dan bertanggung jawab sanggup berkorban dan menghadapi risiko bagaimanapun beratnya. Misalnya, seseorang yang 
sudah berkeluarga dan ada diantara anggota keluarganya terkena penyakit yang sulit disembuhkan, berdasarkan ajaran moral sepantasnya yang sehat memelihara yang sakit dengan tulus ikhlas tanpa ketentuan akhir penantian. Jadi, hendaknya ia menerima musibahyang terjadi dengan penuh tanggung jawab dan keikhlasan.

Keberanian menghadapi risiko merupakan salah satu ciri pelaksanaan tanggung jawab. Nilai seseorang tergantung pada seberapa jauh ia merealisasikan tanggung jawab yang diembankan kepadanya. Dengan kata lain, makin dalam nilai-nilai itu, makin tegas pula seseorang mewujudkan tanggung jawabnya.

Orang Bugis boleh dikatakan sudah banyak yang menduduki jabatan di pemerintahan atau pun di organisasi pemerintah dan swasta. Hal ini didasari oleh keberanian dalam mengerjakan tugas yang diembannya dengan penuh tanggung jawab. Kenapa mereka banyak yang berhasil? Ini disebabkan oleh mereka menerapkan petuah-petuah leluhur yang mereka warisi secara turuntemurun dari orang tuanya dalam bersosialisasi dengan masyarakat sekitarnya.

\section{"Ajak sio mennang mubarani-barani riala ri tau'e.Apa iapa tau riala par'ewa,mulleenngi pogauk i gaukna nawa-nawa'e.Apak ia gaukna nawa- nawa'e pitumpuwangenngi. \\ a. Seuwani, majeppuiwi adek; \\ b. Maduanna, missenngi bettuang; \\ c. Matellunna, magettenngi; \\ d. Maeppakna, metauk i ri Dewata'e; \\ e. Malimanna, naisseppi riyasennge warik; \\ f. Maennenna, majeppui riasennge rapang; \\ g. Mapitunna, naisseng najeppuipi riasenng'e bicara"}

(Mattalitti, 1985: 60)
Terjemahan:

Janganlah kalian memberanikan diri diangkat menjadi pejabat. Sebab orang yang dapat diangkat menjadi pejabat,ialah orang yang sanggup melaksanakan perbuatan pikiran. Adapun perbuatan pikiran itu ada tujuh macam, yaitu:

a. Pertama, mengetahui adat-istiadat;

b. Kedua, mengetahui sopan santun (tata karma);

c. Ketiga, teguh pendirian;

d. Keempat, bertakwa kepada Allah swt.;

e. Kelima, mengetahui yang dimaksud tataan hidup (aturan yang membedakan hal-hal yang pantas);

f. Keenam, mengetahui hukum kias (analog);

g. Ketujuh, mengetahui apa yang dimaksud peradilan (menentukan salah benarnya seseorang).

Petuah tersebut di atas memberikan kejelasan kepada kita agar tidak melakukan suatu pekerjaan bila tidak mampu atau tidak mengetahui dengan pasti pekerjaan itu. Misalnya, berkehendak mau menduduki suatu jabatan tertentu, tetapi kalau tidak mengetahuyi ilmunya atau aturannya lebih baik menolak karena akhirnya nanti yang susah kita sendiri dan juga orang lain.

\section{Manfaat Petuah-Petuah Leluhur}

Petuah-petuah leluhur ini merupakan warisan leluhur orang Bugis yang diwariskan secara turun-temurun, dari satu generasi ke generasi berikutnya. Dalam Silasa I terkandung bermacammacam petuah yang dapat dijadikan pegangan dalam menghadapi berbagai masalah kehidupan, baik yang bersifat duniawi maupun yang bersifat ukhrawi

Dari segi isi dan maknanya, petuah-petuah leluhur dalam Silasa I 
dapat dikelompokkan menjadi beberapa tiga bagian, yakni sebagai nasihat, falsafah hidup, dan perekat hubungan antarindividu.

\subsection{Petuah Sebagai Nasihat}

Petuah berisi nasihat adalah petuah yang ditujukan kepada orang lebih muda. Isinya kebanyakan berupa hal-hal yang patut dilakukan dan perbuatan yang harus dihindari. Meskipun cukup banyak jenis petuah sebagai nasihat, misalnya petuah yang berisi nasihat umum, sebagai nasihat khusus, nasihat untuk remaja, nasihat kepada pemimpin, nasihat kepada pedagang, nasihat kepada suami dan istri, nasihat kepada orang mukmin, dan lain sebagainya, penelitian ini mencontohkan satu petuah sebagai nasihat secara umum.

"Nalebbi'mua enneng lappana adanna sininna anregurukku masero kuelori:

a. Alitutuiwililamu; iyapa mupoadai adae' purapi mutangnga' mutimbangi munappa oadai, apa' iya lilae palori teppudusau.

b. Alitutuiwi matammu; aja'naiya myita pawaekko rija'e.

c. Alitutuiwi tigero'mu; narekko manrekko hallala' epa, apa'iya narekko haram muanre iyanaritu pawako rimaja'e.

d. Altutuiwi gau'mu iyapa mupagau'i purapi mutangnga' mutimbangi nainappa mupogau', iyanritu pawaekko rimadecengnge rilinoe lettu'riahera'.

e. Alitutuiwi doccilimmu; aja' muengkalingai ada temmattujue rilinoe riahera', apa' iya rekko muengkalingaiwi iyanaritu pawao rimaja'e.

f. Rekko makkasiwiyakko ri Allataala kuwaetoppa ripuwang leheremmu, alitutuiwi atimmu kuwammengngi namttette' mangolo ripuwammu.

g. Narekko maeloko riwaramparang akkaresoko riharusu'e, mumatutu passui'i sekke'na massidekkang ripakere'e."

(Machmud, 2001: 110--111).

Terjemahan :

Lebih enam patah perkataan dari guru saya yang paling saya senangi:

a. Jagalah lidahmu; kau ucapkan katakata sesudah meninjau dan menimbangnya, sebab lidah itu melukai yang lambat sembuh.

b. Jagalah matamu; jangan melihat pada yang membawamu pada keburukan.

c. Jagalah tenggorokanmu; kalau makan yang halal, sebab kalau haram yang kau makan itulah yang membawa pada keburukan.

d. Jagalah perbuatanmu; baru dilakukan kalau sudah meninjau dan menimbang itulah yang membawamu pada kebaikan dunia dan akhirat.

e. Jagalah telingamu; jangan mendengar bicara yang tidak bermanfaat di dunia dan di akhirat, sebab kalau engkau mendengarkan itulah yang membawamu pada keburukan.

f. Kalau menghadap kepada Allah atau yang dipertuan, jagalah hatimu supaya tetap menjurus kepada-Nya.

g. Kalau mengingini harta benda berusahalah dengan benar, dan berhati-hati (agar selalu) mengeluarkan zakatnya untuk disedekahkan kepada fakir miskin.

Petuah tersebut di atas mengisyaratkan kepada kepada kita bahwa tidak sedikit orang hanya menuruti kemauan atau nafsunya semata tanpa memikirkan akibatnya. Oleh karena itu, melalui petuah di atas, kita dinasihatkan agar dapat membendung kemauan atau nafsu yang tidak seharusnya dilaksanakan yang mungkin 
mudaratnya jauh lebih banyak dibandingkan dengan kebaikan/manfaatnya pada diri kita sendiri. Jelasnya, petuah tersebut memberikan nasihat kepada kita agar berhati-hati dalam bertindak/berbuat.

\subsection{Petuah Sebagai Falsafah Hidup}

Falsafah hidup orang Bugis dalam tulisan ini dapat diterjemahkan sebagai kumpulan pikiran, sikap, perilaku, dan nilai-nilai budaya orang Bugis dalam menghadapi berbagai masalah kehidupan dan keberadaannya. Jika disimak secara saksama petuah-petuah yang pada Silasa I dapat dikelompokkan menjadi dua bagian, yaitu (1) petuah berisi falsafah hidup yang menggunakan kata-kata denotatif (biasa)agar mudah dimengerti atau dipahami maksudnya dan (2) petuah berisi falsafah hidup yang menggunakan kata-kata kiasan (petuah filosofis) karena memerlukan perenungan lebih mendalam untuk memahami maknanya. Salah satu contoh petuah berisi falsafah hidup yang menggunakan kata-kata kiasan adalah sebagai berikut.

\section{"Eppa' paramata matappa'na tauwe: \\ a. Lempu'e \\ b. Ada tongeng sibawa nyameng kininnawa \\ c. sirik sibawa getteng \\ d. nawa-nawa sibawa ati mapaccing."}

(Machmud, 2001: 75--76)

Terjemahan:

Empat permata bercahaya pada manusia.

a. Kejujuran

b. Kata benar bersama keikhlasan

c. Rasa malu (sirik) bersama keteguhan

d. Akal bersama baik hati.

Kutipan tersebut menjelaskan bahwa ada empat butir yang harus dijadikan bahan pertimbangan dalam mengambil keputusan, yaitu kejujuran, keikhlasan, sirik, dan akal bersama baik hati. Keempat butir itu merupakan penjelmaan jiwa yang besar terhadap diri manusia. Itulah sebabnya jika empat sifat tersebut hilang akan menurunkan derajat kemanusiaannya sebagai manusia seutuhnya. Orang yang mempunyai kepribadian yang kuat, jujur, berakal, dan mempunyai harga diri akan tetap bercahaya di mata masyarakat.

Petuah berisi fasafah hidup yang menggunakan kata-kata kiasan atau petuah yang filosofis agak sulit dipahami karena banyak menggunakan kata-kata kiasan. Petuah jenis inidiperlukan perenungan secara mendalam jika ingin dipahami maksud yang terkandung di dalamnya.Salah satu contoh petuah filosofis dapat dilihat pada contoh berikut.

"Aja' muancaji cakke awo".

(Machmud, 2001: 81)

Terjemahan:

Jangan menjadi tangkai bambu.

Kutipan petuah leluhur di atas menjelaskan agar orang janganlah selalu berbuat curang terhadap orang lain sebagaimana kira-kira makna yang terkandung dalam kutipan tersebut bahwa tangkai bambu itu bentuknya kecil lagi keras, bilamana ada orang yang lewat atau ada orang yang langgar di dekatnya akan tergores atau tertusuk. Demikianlah dikiaskan bagi orang yang suka merusak setiap orang yang suka berhubungan dengannya.

\subsection{Petuah Sebagai Hubungan Antarindividu}

Pengalaman mengajarkan bahwa tidak mungkin kita hidup sendiri dalam masyarakat. Setidak-tidaknya, dalam hal tertentu, pasti memerlukan bantuan dari orang lain. Hubungan antarindividu atau 
antarkelompok itu merupakan sesuatu yang ideal. Maka tidak salah apabila penulis mengatakan bahwa orang yang terkucilkan dalam pergaulan masyarakat adalah orang yang menderita batin. Contoh petuah leluhur yang dapat dijadikan pedoman dalam menjalin hubungan antar individu adalah sebagai berikut.

"Tassisampoang uring-lowa', tassisebbokeng pamuttu"

(Machmud,2001: 41--42)

Terjemahan:

Tidak saling menutupkan belanga, tidak saling membocorkan kuali.

Makna dari petuah di atas adalah bahwa tolong-menolong dan saling bantu dengan ikhlas menyelesaikan sebuah pekerjaan akan menghasilkan pekerjaan yang baik. Mutiara bertambah indah karena diuntai menjadi perhiasan, seindah hidup bila dijalin dengan saling pengertian dan kerja sama yang baik. Biarkan keinginan menolong itu keluar dari lubuk hati yang mencari kenikmatan dan kepuasannya dalam menolong orang lain karena itulah jalan untuk menghilangkan kehausan hati yang mencari kebaikan dan kebenaran.

\section{Penutup}

Petuah-petuah leluhur dalam Silasa I merupakan salah satu jenis sastra lisan Bugis yang hingga saat ini masih tetap hidup dan dihayati, terutama mereka yang berlatar belakang budaya Bugis dan penutur bahasa Bugis. Jenis sastra lisan ini merupakan warisan leluhur orang Bugis yang disampaikan secara turun temurun, dari satu generasi ke generasi berikutnya. Oleh karena itu, jenis sastra lisan itu perlu dicegah dari kepunahannya, baik melalui penginventarisian maupun melalui penelitian yang lebih mendalam dan menyeluruh. Silasa I dalam kedudukannya sebagai sastra daerah sarat dengan nilai-nilai budaya yang perlu diketahui dan diamalkan dalam kehidupan masyarakat.

Salah satu tujuan petuah leluhur diajarkan adalah agar ajaran moral yang terkandung didalamnya dapat dijadikan sebagai penapis agar tidak terbawa arus kurang terpuji yang bisa merusak moral generasi muda. Dari analisis data ditemukan beberapa nilai budaya dalam Silasa I, yaitu (1) kejujuran, (2) sirikberani-penakut, dan (3) tanggung jawab.

Nilai-nilai budaya dan manfaat Silasa I pada dasarnya masih tetap relevan dengan kehidupan sekarang, walaupun hal tersebut mengalami pengembangan sesuai dengan situasi sekarang. Ada beberapa manfaat yang dimunculkan dalam tulisan ini, yaitu sebagai (1) bahan nasihat, (2) falsafah hidup, dan (3) perekat hubungan antarindividu.

Silasa I sebagai salah satu bentuk bahan nasihat, falsafat hidup, dan pererat hubungan antarindividu dengan menggunakan bahasa simbol sangat perlu digali lebih mendalamagar nilai-nilai yang terkandung di dalamnya dapat lebih transparan. Oleh karena itu, pengungkapan sebanyak tiga nilai dan tiga manfaat di dalam penelitian ini tidaklah berarti bahwa hanya nilai-nilai dan manfaat itu yang ada. Untuk membuktikan hal itu, tulisan lanjutan masih tetap diperlukan.

\section{Daftar Pustaka}

Abidin, Andi Zainal. 1983. Persepsi Orang Bugis Makassar tentang Hukum, Negara dan Dunia Luar. Bandung: Penerbit Alumni.

Amir, Andi Baso. 1966. "Pokok-pokok Pikiran tentang Sirik di Sulawesi Selatan." Watampone: Makalah 
Seminar Kebudayaan Bugis Daeah Bone.

Enre, Fakhruddin Ambo. 1986.

Pappasengna To Macca'e ri Luwu

Sibawa Kajao laliqdong ri Bone.

(Transliterasi dan Terjemahan ke dalam Bahasa Indonesia). Ujung Pandang: Proyek Tulisan dan Pengkajian Kebudayaan Sulawesi Selatan.

Peningkatan Kulaitas Generasi.
Makalah

Alwi, Hasan, dkk. 2005. Kamus Besar

Bahasa Indonesia. Edisi III.

Jakarta: Balai Pustaka. Departemen

Pendidikan Nasional.

Koentjaraningrat. 1984. Kebudayaan Mentalitas dan Pembangunan. Jakarta: PT Gramedia.

Liang Gie, The. 1976. Garis Besar Estetika (FilsafatKeindahan). Yogyakarta: Karya Kencana.

Machmud, Andi Hasan. 2001..Silasa I. Ujung Pandang: Perwakilan Departemen Pendidikan dan Kebudayaan Propinsi Sulawesi Selatan.

Murmahyati. 2000. Nilai Edukatif Pappaseng dalam Sastra Bugis. Makassar: Balai Bahasa Ujung Pandang.

Mustafa. 2010. Peranan "Pappaseng Tomatoa" dalam Kehidupan Kita Relevansinya Dengan Masa Kini" (Makalah Seminar dalam Rangka Bulan Bahasa di Makassar Golden Hotel).

Moein MG, A. 1977. Menggali Nilai Sejarah Kebudayaan Sulselra: Sirik dan Pacce. Ujung Pandang: SKU Makassar Press.

Palippui, H., Hatta, Muhammad., Mappa, Moch Said., Pabarangi, Andi. 1992. Ada Sulasana Ugi Masagala'e. Sengkang: Yayasan Kebudayaan Mini Latenribali.
Rahim, A. Rahman. 1985. Nilai-nilai Utama Kebudayaan Bugis. Hasanuddin University Press: Ujung Pandang.

Syamsudduha. 2012. "Pendidikan Nilai dan Karakter dalam Pappaseng: Representasi Norma dan Falsafah Hidup Masyarakat Bugis."(Prosiding: Kongres Internasional II Bahasa-Bahasa Daerah Sulawesi Selatan Tahun 2012. Tanggal 1 - 4 Oktober 2012 di Hotel Sahid Jaya Makassar.

Teew, A. 1982. Khazanah Sastra Indonesia. Beberapa Masalah dan Penyebaranya. Jakarta: Gramedia.

--------. 1988. Sastra dan Ilmu Sastra: Pengantar Ilmu Sastra. Jakarta: Pustaka Jaya-Girimukti Pasaka.

Wellek, Rene dan Austin Warren. 1990.Teori Kesusastraan. Diterjemahkan oleh Melani Budianta. Jakarta: PT Gramedia. 